DOI 10.37882/2500-3682.2020.07.04

\title{
ПРИОРИТЕТЫ В СОВРЕМЕННОМ РАЗВИТИИ ЦЕННОСТНЫХ ОРИЕНТАЦИЙ БЕЗРАБОТНЫХ В ПЕРИОД НЕНОРМАТИВНОГО КРИЗИСА ЗАНЯТОСТИ
}

\section{PRIORITIES IN THE MODERN DEVELOPMENT OF VALUE ORIENTATIONS OF THE UNEMPLOYED DURING THE NON-NORMATIVE EMPLOYMENT CRISIS}

\section{Belousov}

Summary: Priorities in the modern development of value orientations of the unemployed during the non-normative employment crisis are individual for everyone and have a special impact not only on the professional path of a person, but also on the development of the individual as a whole. The modern labor market is volatile and dictates its own conditions. If earlier a person's career development was built quite consistently, and often meant professional self-determination in only one area or a maximum of two, in modern realities, a person is forced to change the professional sphere from 2 to 4 times during his life. The article presents the results of a study aimed at setting priorities in the development of value orientations of unemployed citizens of various social groups who are experiencing certain difficulties, including psychological ones, when they are in a situation of non-normative employment crisis, i.e. they are out of work as a result of any unforeseen circumstances.

Keywords: professional self-determination, non-normative employment crisis, professional orientation, psychological adaptation professional retraining, psychological diagnostics.
Ц енностные ориентации людей в условиях неожиданной потери работы влияют непосредственным образом на дальнейшее профессиональное самоопределение, которое является одним из важнейших проявлений психического развития личности. Большинство людей нацелено на выполнение социально значимой деятельности, основным направлением которой является производство продукта, имеющего определенную социальную ценность, является критерием смысловых и мотивационных поисков и решений человека. (Климов Н.C 1999). Ранее устоявшаяся парадигма развития профессионального самоопределения состоит из структуры, включающей в себя:

- Соотнесение человеком себя к определенному профессиональному сообществу (учителя, врачи, инженеры и т.д.)

- Оценки собственного соответствия занимаемого
Белоусов Максим Владимирович

Московский Государственный Психолого-Педагогический

университет,

Belmax777@mail.ru

Аннотация: Приоритеты в современном развитии ценностных ориентаций безработных в период ненормативного кризиса занятости для каждого индивидуальны и оказывают особое влияние не только на профессиональный путь человека, но и на развитие личности в целом. Современный рынок труда изменчив и диктует свои условия. Если раньше у человека карьерное развитие выстраивалось достаточно последовательно, и часто подразумевало профессиональное самоопределение только в одной сфере или максимум в двух, то в современных реалиях, человек вынужден менять профессиональную сферу от 2 до 4 раз в течение своей жизни. В статье представлены результаты исследования, целью, которого было установить приоритеты в развитии ценностных ориентаций безработных граждан различных социальных групп, испытывающих определенные сложности, в том числе и психологического плана, при нахождении в ситуации ненормативного кризиса занятости, т.е. оказавшихся без работы в результате каких-либо непредвиденных обстоятельств.

Ключевые слова: профессиональное самоопределение, ненормативный кризис занятости, профессиональная ориентация, психологическая адаптация профессиональное переобучение, психологическая диагностика.

места в профессиональном сообществе («начинающий», «профессионал»).

- Знания о собственных выраженных слабых и сильных сторонах, индивидуальных стратегиях самосовершенствования и повышения эффективности, об особенностях стиля собственной деятельности.

- Формализованного представления о своем профессиональном будущем.

В текущей ситуации, сложившейся на современном рынке труда, безработный осознает, что в силу быстро меняющихся обстоятельств, он вынужден часто отходить от четкого плана, связанного с выбором одной профессии, ему приходится для достижения успеха прибегать к большей избирательности, анализируя свой дальнейший карьерный путь. Более того постоянно самосовер- 
шенствоваться в новых условиях, меняя профессии и постоянно обучаясь. Действуя таким способом ему, в конце концов, удастся добиться необходимой рефлексии для получения новой работы или профессии.

Так же необходимо учесть психоэмоциональное состояние безработных в период ненормативного кризиса занятости. Профессиональное самоопределение безработного, как правило, имеет всокую степень эмоциональной окраски, причиной которой являются различные обстоятельства из жизни человека временно оказавшегося в ситуации отсутствия работы. Убежденность в предопределенности ошибочного выбора профессиональной деятельности, который ранее казался совершенно осмысленным и верным превращается в тяжелую ношу. Невозможность установки причинноследственной связи между прошлым и настоящим, формирует убеждение у безработного, искать что-то новое в профессиональной среде и меняться, совершенно бесполезно и не эффективно с точки зрения быстрого нахождения работы по изученному сценарию. Подобная тактика в современной ситуации на рынке труда часто терпит фиаско и только удлиняет срок нахождения человека в ситуации ненормативного кризиса занятости. Для определения наиболее частых моделей поведения безработных, мешающих поиску работы, было проведено исследование, в котором участвовали представители различных социальных групп с разным периодом нахождения в статусе безработного. Таким образом, цель исследования:

Целью исследования было эмпирическое изучение приоритетов развития ценностных ориентаций безработных в период ненормативного кризиса занятости.

Тематика данного исследования определяется следующими обстоятельствами:

- рост числа безработных граждан, оказавшихся в ситуации ненормативного кризиса занятости и отсутствие у них результативных стратегий по поиску новой работы или переобучению, отвечающих современных требованиям рынка труда. Данный фактор влечет за собой перспективу напряженности в различных системах взаимоотношений безработных людей и не может быть недооценен.

- увеличение невостребованных или недостаточно востребованных профессий при наличии большого количества специалистов в данных профессиональных областях и, как следствие, появление серьезных психологических кризисов у безработных граждан в условиях отсутствия профессиональной занятости. Подобное состояние, выражающееся в первую очередь в виде обесценивания самого факта трудоустройства, в случае если устроиться про привычному механизму или на должность похожую с ранее занимаемой, не удается.

- отсутствие понятных и удобных механизмов для оценки и изучения собственных личностно-профессиональных качеств, влияющих на выбор или смену профессиональной деятельности, подталкивающих к необходимости переобучения, либо делающих подобный выбор невозможным.

Выборка исследования представлена безработными людьми, обращающимися в территориальный Центр Занятости Населения (ЦЗН) в одном из районов Тульской области для поиска возможного трудоустройства. Общее количество респондентов составило 135 человек, из них 62 (\%) мужчин и 38 (\%) женщин. В соответствии с задачами исследования, выборка была разделена на четыре группы с разным социальным статусом и мотивацией для профессионального самоопределения:

- 1 группа: безработные граждане, обратившиеся в ЦЗН без интервала между предыдущими местами работы более 3 месяца

- 2 группа: безработные граждане, обратившиеся в ЦЗН, с большим пробелом в трудовой деятельности от 1,5 лет, перенесшие опасные для жизни заболевания, лица, по каким-то причинам, не имевшие возможности к трудовой деятельности.

- 3 группа: безработные граждане, неоднократно обращающиеся и находящиеся в поиске работы через ЦЗН от 5 месяцев. Обращающиеся в ЦЗН неоднократно.

\section{Методы и методики исследования}

Для решения задач исследования были использованы:

- Опросник «Определение ценностных ориентаций» по методике М.Рокича. Где исследуются два класса ценностей:

Терминальные ценности - это убеждения в том, что цель, связанная с индивидуальным существованием человека крайне важна и непосредственный смысл, в ее достижении;

Инструментальные ценности - это убеждения в том, что та или иная модель поведения, выраженная в конкретных действиях, а так же индивидуальные особенности личности являются определяющими в любой ситуации.

Участнику исследования, представляющему какую-либо из трех вышеописанных групп, предлагается заполнить два списка ценностей (по 18 в каждом), на листах бумаги формата A4, в алфавитном порядке. В этих списках участник исследования присваивает каждой ценности соответствующий ранговый номер. Сначала предоставляется набор терминальных ценностей, а затем набор инструментальных ценностей.

- Опросник «Самооценка психических состояний» 
по методике Г. Айзенка. Опросник включает описания психоэмоциональных состояний, наличие которых у себя участнику исследования необходимо опровергнуть либо подтвердить. Данный опросник позволяет определить уровень фрустрации, тревожности, фрустрации, ригидности, агрессии. Каждому участнику исследования предлагается заполнить опросник из 40 предложений.

- Опросник «Определение типа личности» по методике Дж. Холланда (Романова Е.А. 1999). Опросник профессиональных предпочтений соотносит интеллектуальные способности и склонности, при новом профессиональном самоопределении, с которым часто сталкиваются безработные в современных условиях. Выделяются типы личности по предрасположенности к конкретной профессии:

Артистический, интеллектуальный, конвенциальный, предприимчивый реалистический тип, социальный. Тип профессии, к которому имеется максимальная предрасположенность, определяется наиболее предпочитаемыми профессиональными сферами.

Сотрудникам Центра Занятости Населения для проведения опроса была предоставлена анкета, опрос проводился на условиях анонимности. В анкете указывался пол, возраст, причины, побудившие респондента к смене профессиональной деятельности, приоритеты для выбора новой профессии, так же прилагался лист для ответов на предложенные опросники. После проведения собеседования сотрудник Центра Занятости населения, делал отметки закрепляя респондента за одной из вышеописанных групп исходя из его статуса на момент поиска работы. После проведения исследования результаты опроса соотносились с внешними и внутренними факторами, влияющими на развитие ценностных ориентаций безработных в период ненормативного кризиса занятости.

\section{Результаты исследования}

Анализ полученных данных показал, что для:

- первой группы участников исследования (безработные граждане, обратившиеся в ЦЗН без интервала между предыдущими местами работы более 3 месяца) характерно:

Преобладание в системе ценностных ориентаций терминальных ценностей: конкретных и самореализации, выраженных в подавляющем большинстве в активной и деятельной жизни (75\% от общего количества участников группы). А так же инструментальных ценностей: индивидуалистических и межличностного общения, выраженных в стремлении к независимости и образованности (84 процента от общего количества участников группы). Тревожность у участников данной группы либо отсутствует, либо присутствует на минимальном уровне. Средний балл по тесту Айзенка -2 (от 0-до 7 баллов отсутствие тревожности по тесту Айзенка), низкая степень фрустрации средний балл -8 (от 8-до 14 баллов средний уровень фрустрации по тесту Айзенка), спокойствие и выдержанность, средний балл агрессии -8(от 8-до 14 баллов средняя выраженность агрессии по тесту Айзенка), быстрая переключаемость как фактор отсутствия ригидности, средний балл ригидности 2 (от 0 до 7 баллов отсутствие ригидности). Предприимчивый (41\% от общего числа участников группы) и реалистичный (38\% от общего числа участников группы) типы личности (Опросник Холланда) составляют подавляющее большинство в исследуемой группе. Данные результаты характеризуют участников данной группы как людей, имеющих высокую готовность к риску и лидерские качества, энергичных, а порой даже и импульсивных, при наличии хорошей способности концентрировать внимание и различных двигательных навыков, нацеленных на конкретный результат, с потребностью практического использования ресурсов. Данные типы личности наиболее часто успешно себя реализуют в менеджменте различных уровней и сфер, в том числе находящихся в кризисном состоянии консалтинга. Они часто встречаются среди представителей профессий связанных с обработкой и генерацией информационного поля. Сюда относятся различные технические направления технологий, включающие, как и технический персонал, так и инженеры, управляющие производственными и технологическими процессами.

- второй группе участников исследования: безработные граждане, обратившиеся в ЦЗН, с большим пробелом в трудовой деятельности от 1,5 лет, перенесшие опасные для жизни заболевания, лица, по каким-то причинам, не имевшие возможности к трудовой деятельности, характерно: Преобладание в системе ценностных ориентаций терминальных ценностей: конкретных, выраженных в подавляющем большинстве в достижении крепкого здоровья и наличия хороших и верных друзей (82\% от общего количества участников группы). А так же инструментальных ценностей: этических и конформистских, выраженных в ответственности и терпимости (69\% от общего числа участников группы) Высокий уровень тревожности, средний балл- 15 (от 15 до 20 баллов высокий уровень тревожности). Фрустрация среднего уровня, средний балл- 9, (от 8 до 14 баллов средний уровень фрустрации) спокойствие и выдержанность, средний балл агрессии -1 (от 0-до 7 баллов отсутствие агрессии) Средний уровень 
ригидности, средний балл- 9 (от 8 до 14 баллов средний уровень ригидности). Интеллектуальный (44\% от общего числа участников группы) и артистический (40\% от общего числа участников группы) типы личности (Опросник Холланда) составляют подавляющее большинство в исследуемой группе. Данные результаты характеризуют участников данной группы как людей с аналитическим складом ума, ориентированных на реализацию различных интеллектуальных задач, с хорошими навыками воображения, имеющих тенденции к избеганию контроля их деятельности и следованию общим регламентам принятым на рабочем месте, тенденция к снижению контактов в профессиональной деятельности. Данные типы личности наиболее часто успешно реализуют себя в научной среде, часто подобный тип личности встречается среди программистов, наиболее приемлемым графиком работы и взаимодействия с заказчиком (работодателем), выбирающих удаленную работу с выполнением одноразовых контрактов без длительных договорных взаимоотношений с заказчиком. Сюда относятся различные творческие направления профессиональной деятельности: искусство, режиссура, дизайн и другие.

- третьей группе: безработные граждане, неоднократно обращающиеся и находящиеся в поиске работы через ЦЗН от 5 месяцев. Обращающиеся в ЦЗН неоднократно.

Преобладание в системе ценностных ориентаций терминальных ценностей: конкретных ценностей и профессиональной самореализации, выраженных в подавляющем большинстве в стремлении к материально-обеспеченной жизни и общественному признанию (89\% от общего количества участников группы) А так же инструментальных ценностей: индивидуалистических и самоутверждения, выраженных в рационализме и независимости (71\% от общего количества участников группы). Средний уровень тревожности, средний балл- 9 (от 8 до 14 баллов средний уровень тревожности). Фрустрация среднего уровня, средний балл- 10, (от 8 до 14 баллов средний уровень фрустрации). Средний уровень агрессии -11 (от 8 до 14 баллов средний уровень агрессии). Средний уровень ригидности, средний балл- 10 (от 8 до 14 баллов средний уровень ригидности) Конвенциональный (39\% от общего числа участников группы) и рациональный (40\% от общего числа участников группы) типы личности (Опросник Холланда) составляют подавляющее большинство в исследуемой группе. Данные результаты показывают, что для данной группы участников исследования характерны: деловитость и рациональность, исполнительность и конформизм консервативность, хорошая исполнительность в сочетании с ориентацией на конкретный результат. Тенденция к работе по четко прописанной инструкции и избегание каких-либо ситуаций, связанных с неопределенностью. Данные типы личности наиболее успешно реализуют себя в тех видах профессиональной деятельности, где требуется обработка информации часто рутинного характера, это бухгалтера, банковские служащие, экономисты, логисты, так же сферы ориентированные на решение конкретных задач по предоставлению какой либо услуги: шоферы, парикмахеры, работники сельскохозяйственной отрасли.

\section{Выво}

По результатам проведенного исследования автором статьи делается следующий вывод: в первой группе, где участники менее всего по периоду времени искали в течении своей жизни новую работу, основной акцент идет на самореализации и активности. Так же у участников практически отсутствует тревога, фрустрация и ригидность, и агрессивность, выражены лидерские качества. Безусловно, в первую очередь данные показатели сравниваются с третьей группой, так как фактически ситуация у участников первой и третьей групп схожа, при том, что участники первой группы трудоустраиваются значительно быстрее. Из чего можно сделать вывод, что отсутствие тревоги и ригидности наиболее важно для быстрого поиска работы. Так же наиболее важным фактором для эффективного поиска работы в кратчайшие сроки является наличие лидерских качеств, и потребность в самореализации и независимости. Так же имеет смысл обратить особое внимание на выраженную потребность в сохранении здоровья, важности в наличии друзей и терпимости у респондентов второй группы. Здесь важно обратить внимание, что люди, долгое время не имеющие возможности трудоустройства из-за неожиданной потери работы, попадая в ненормативный кризис занятости, часто не имея возможности вернуться на прежнее место работы или получить ранее занимаемую должность, достаточно быстро разочаровываются в поиске новой работы. После чего возможность получить альтернативную работу, исходя из новых условий своей трудоспособности, попросту обесценивают. Около половины безработных воспринимают вынужденную незанятость как трагедию, равную по силе или большую, чем развод и его последствия. (Е.А. Толочек 1999) Понимание мотивации безработных граждан оказавшихся в ненормативном кризисе занятости, имевших длительный период из-за потери трудоспособности (участники исследования второй группы), поможет сотрудникам Центров занятости населения проводить консультирование подобных граждан более эффективно и помогать в получении навыков решения проблем, связанных с реализацией профессиональной карьеры, в том числе, умение преодолевать стрессовые состояния, анализировать информацию и осуществлять деловое общение; способствовать реализации готовности безработного к активному и самостоятельному решению своих про- 
фессиональных проблем; способствовать оптимизации эмоционального состояния и уровню самооценки безработных. (Бендюков В.А 2008).Часто сотрудники центров занятости, а именно те кто занимается профессиональным консультированием фактически становятся посредниками между человеком и определенной социально-профессиональной группой, проводя процесс консультирования безработных граждан. (Е.Ю. Пряжникова, Н.С. Пряжников 2010) Главная (идеальная) цель такого процесса - постепенное формирование у человека внутренней готовности самостоятельно и осознанно планировать, корректировать и реализовывать перспективы своего развития (профессионального, жизненного, личностного), другими словами - помогать человеку расширять свои возможности в рамках определенного времени, пространства и смысла и претворять их в жизнь. (Е.А. Толочек 1999).

\section{ЛИТЕРАТУРА}

1. Толочек В. А. “ Современная психология труда”. Учебное пособие. - СПб.: Питер, 2005 стр.334, 335, 336, 353, 354

2. Климов Е.А. “Психологическая диагностика в управлении персоналом” Учебное пособие для сотрудников кадровых служб Российское психологическое общество Москва 1999 стр. 16, 17,18

3. Романова Е. С"99 популярных профессий". Психологический анализ и профессиограммы. 2-е изд. СПб.: Питер, 2003 стр 14, 15.

4. Пряжников Н.С. Теория и практика профессионального самоопределения. Учебное пособие. - М.: МГППИ, 1999 стр.24.25.26.

5. Бендюков В.А. Исследование эффективности индивидуального психологического профконсультирования безработных в службе занятости. Известия Российского Государственного педагогического Университета им А.И. Герцена.

6. Е.Ю. Пряжникова, Н.С. Пряжников. Профориентация. 5-е изд, исправленное и дополненное. Москва. Издательский центр «Академия», 2010 стр .220

(с) Белоусов Максим Владимирович (Belmax777@mail.ru).

Журнал «Современная наука: актуальные проблемы теории и практики»

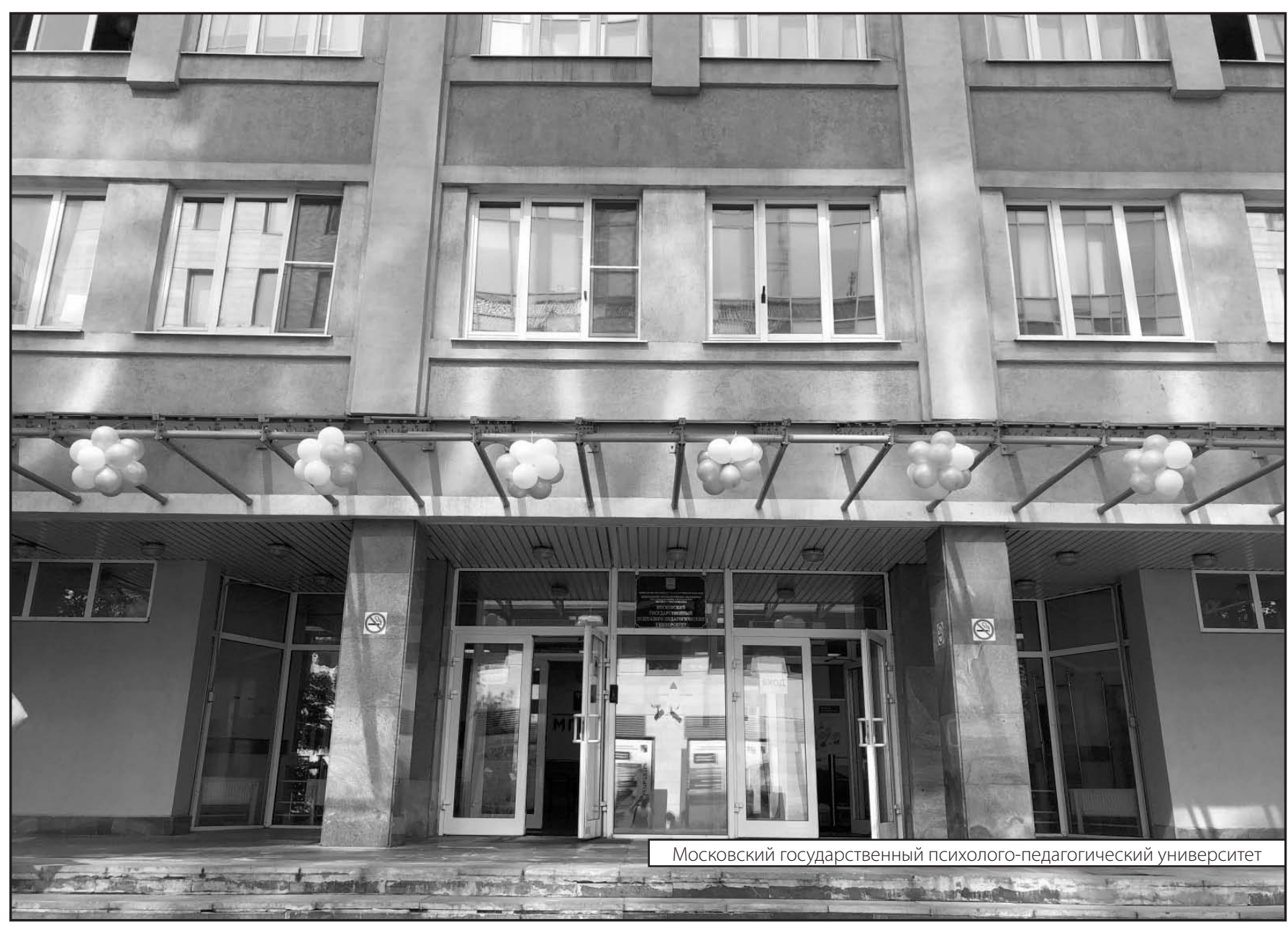

